\title{
Water-stained leaves: formation and application as a field indicator of wetland hydrology
}

\author{
Jacob F. Berkowitz ${ }^{1}$ (1) Jason P. Pietroski ${ }^{2}$
}

Received: 27 November 2020 / Accepted: 22 September 2021 / Published online: 18 October 2021

This is a U.S. government work and not under copyright protection in the U.S.; foreign copyright protection may apply 2021

\begin{abstract}
Wetland delineations conducted in the United States utilize field indicators as proxy measures of the presence or absence of wetland hydrology. Water-stained leaves provide a practical, qualitative field indicator of wetland hydrology; however, the formation of water-stained leaves has not been elucidated. In response, leaves from six tree species were examined under five treatments to investigate the water-staining process and concomitant timeframes. Results indicate that leaf staining occurred within 14-21 days of continuous exposure to wetland waters and sediment under both laboratory and field conditions. Leaf staining was characterized by readily observable shifts in leaf color (i.e., decreasing Munsell hue, value, and chroma) causing the leaves to appear very dark or black. No color shifts associated with leaf staining occurred in treatments exposed to upland conditions. The timeframe associated with leaf staining corresponds with established wetland hydrology criteria requiring a minimum hydroperiod of 14 consecutive days of soil saturation, flooding, or ponding. Leaves exposed to wetland waters and sediment underwent color shifts significantly faster and to a greater extent than leaves inundated with deionized water, likely as a result of increased microbial abundance and the presence of anaerobic conditions in the simulated wetland treatments. Results suggest that water-stained leaves 1) are a useful and reliable wetland hydrology field indicator for wetland delineation purposes, 2) may provide a proxy measure of wetland hydroperiod, and 3) Munsell color measurements can help differentiate between leaves exposed to wetland and upland conditions.
\end{abstract}

Keywords Wetland delineation $\cdot$ Field indicators $\cdot$ Hydrology $\cdot$ Sediment $\cdot$ Munsell color

\section{Introduction}

The U.S. Army Corps of Engineers (USACE) along with the U.S. Environmental Protection Agency maintains responsibility for the regulation of certain aquatic resources, including wetlands, in the United States as outlined in the Clean Water Act (National Research Council 1995). In order to implement the provisions of the Clean Water Act, procedures were developed to identify these aquatic resources and delineate their boundaries (Cowardin et al. 1979; Tiner 1993), resulting in the publication of the Corps of Engineers Wetlands Delineation Manual (Corps Manual; Environmental Laboratory 1987). The Corps Manual outlines a

Jacob F. Berkowitz

Jacob.F.Berkowitz@usace.army.mil

1 US Army Corps of Engineers, Engineer Research and Development Center, Vicksburg, MS 39180, USA

2 US Army Corps of Engineers, Portland District, Portland, OR 37204, USA three-factor approach to wetland identification and delineation based upon the presence or absence of 1) hydrophytic vegetation, 2) hydric soils, and 3) wetland hydrology (Tiner 2016).

Several studies have examined the development of hydric soils and hydrophytic vegetation communities and address the application of those factors for wetland delineation. These studies identify the biological, chemical, and physical factors required for hydric soils and hydrophytic plant communities to perform wetland functions. Examples from the hydric soils literature include the following research efforts. Megonigal et al. (1993) demonstrated the utility of soil morphological features in estimating periods of saturation, while others describe the application of iron transformations and soil hydromorphic features as indicative of wetland conditions (Faulkner and Patrick 1992; Wakeley et al. 1996; Vepraskas and Faulkner 2001). Vepraskas (2001) investigated the presence of hydric soils in relation to water table level and the duration of soil saturation. Richardson and Vepraskas (2001) provide an overview of hydric 
soil formation, morphology, and classification, and discuss applications for wetland delineation. These studies, along with many others, form the basis for the development of field indicators of hydric soils which are used to identify and delineate wetlands in the United States (Hurt and Brown 1995; Berkowitz et al. 2021). In addition, the National Technical Committee for Hydric Soils regularly updates field indicators of hydric soils based upon scientific studies linking the functional status of hydric soils with distinct morphological characteristics (USDA-NRCS 2018).

Multiple publications also discuss the use of hydrophytic plant community indicators for wetland delineation. For example, Tiner (1991) outlined the concept of a hydrophyte, identified characteristics of wetland plant communities, and discussed applications for wetland delineation. Cronk and Fennessy (2001) evaluated hydrophyte biology and the use of wetland vegetation in the delineation of wetlands. Additionally, a National Technical Committee for Wetland Vegetation was established to provide science-based guidance on hydrophytic plant occurrence and distribution; informing and improving the development of field indicators of hydrophytic vegetation (Lichvar et al. 2012; Tiner 2012).

In contrast to available literature on hydric soils and hydrophytic vegetation, relatively few studies examine the period of saturation, inundation, or flooding required for wetland hydrologic indicators to develop in the context of wetland identification and delineation. Price and Waddington (2000) provide a review of hydrology studies in wetlands focusing on water quality and restoration, but do not consider wetland delineation. A recent study by Price and Berkowitz (2020) quantified the implications of floodplain inundation patterns for wetland functions but did not concurrently evaluate data related to the field indicators of wetland hydrology used for wetland delineation. The Corps Manual describes wetland hydrology concepts and defines wetland hydrology as being present in "areas that are periodically inundated or have soils saturated to the surface at some time during the growing season" (Environmental Laboratory 1987). The document also indicates that hydrology is often the least exact of the three wetland delineation factors and other publications describe the field indicators of wetland hydrology as more transitory than indicators of hydrophytic vegetation or hydric soils, because some field indicators of wetland hydrology (e.g., surface water) are naturally temporary or seasonal and may be affected by recent or long-term meteorological conditions (USACE 2010).

The field indicators of wetland hydrology are designed to demonstrate that an area experiences periods of soil inundation, flooding, or ponding at a frequency and duration capable of supporting hydric soils and hydrophytic vegetation. These field indicators of wetland hydrology included surface inundation, soil saturation, watermarks on trees, drift lines, sediment deposits, drainage patterns, water-stained leaves, and others (Environmental Laboratory 1987). Subsequently, the list of wetland hydrology indicators was expanded to account for regional variability in wetlands based on the recommendations of the National Research Council (1995) and improvements in wetland science (Wakeley 2002; USACE 2010).

The presence of water-stained leaves is an approved field indicator of wetland hydrology throughout the United States and is frequently observed during wetland determinations. Berkowitz (2011) indicated that water-stained leaves was one of the most common field indicators of wetland hydrology; documented at $>25 \%$ of the 232 study locations included in a survey of wetland delineations occurring across 37 states. The water-stained leaves field indicator of wetland hydrology is described by USACE (2010) as "fallen or recumbent dead leaves that have turned grayish or blackish in color due to inundation for long periods". However, the processes and formation timeframes associated with leaf water-staining remains unknown, and questions persist as to whether the presence of water-stained leaves is an effective and reliable field indicator of wetland hydrology. In response, the current study investigates 1) the water-stained leaf formation process under a variety of simulated wetland and upland scenarios and 2) the rate of leaf staining.

\section{Methods}

Leaves were collected in the vicinity of Vicksburg, MS, USA during late October when natural abscission was occurring. Leaves were removed by hand from tree branches within 2.5 $\mathrm{m}$ of the ground surface, and no leaves were collected from trees $<5 \mathrm{~m}$ in height or from trees exhibiting any signs of damage or disease. Selected species (and wetland indicator status rating in the Atlantic Gulf Coastal Plain region) included Quercus nigra (water oak; facultative), Populus deltoides (eastern cottonwood; facultative), Fraxinus pennsylvanica (green ash; facultative wetland), Salix nigra (black willow; obligate wetland), Platanus occidentalis (American sycamore; facultative wetland), and Acer saccharum (sugar maple; facultative upland) (USACE 2018). Five replicate leaves from each species were evaluated for a period of 56 days under five treatments in order to determine the timing and extent of leaf staining under simulated wetland and nonwetland conditions (Table 1). The treatments were selected to investigate whether colors associated with water-stained leaves would occur under simulated and field wetland conditions, and whether similar color shifts would occur under simulated non-wetland conditions. The inclusion of sediment and different water sources (i.e., wetland water, deionized water) in some treatments was intended to account for potential microbial effects on leaf color changes. 
Table 1 Water-stained leaf study treatments

\begin{tabular}{lll}
\hline Treatment & Description & Location \\
\hline SED & $\begin{array}{l}\text { Leaves submerged in wetland water with } \\
\text { sediment }\end{array}$ & Lab \\
LF & $\begin{array}{l}\text { Leaves submerged in a lacustrine fringe } \\
\text { wetland at variable temperature }\end{array}$ & Field \\
DI & $\begin{array}{l}\text { Leaves submerged in DI water with no } \\
\text { sediment }\end{array}$ & Lab \\
UP & $\begin{array}{l}\text { Leaves remained dry with no sediment } \\
\text { UP-SED }\end{array}$ & Leaves remained dry with sediment \\
\hline
\end{tabular}

The treatments conducted in the laboratory (SED, DI, UP, UP-SED) were maintained at $25^{\circ} \mathrm{C}$ for the duration of the experiment. The field treatment fully submerged leaves (inundation depths ranged from $5-10 \mathrm{~cm}$ ) in a lake fringe wetland (LF) that experienced average daily air temperatures ranging from $13^{\circ} \mathrm{C}$ to $27^{\circ} \mathrm{C}$ during the study, the leaves were exposed to light, and the entire experiment was conducted during the growing season. Simulated wetland laboratory treatments (SED) utilized wetland water collected from the same lacustrine fringe wetland used in the field experiment (LF). The DI treatment utilized laboratory-grade deionized water. Treatments that included sediment (SED, UPSED) used materials from the A horizon of Memphis silt loam (14.2\% sand, $78.3 \%$ silt, and $7.5 \%$ clay), a Fine-silty, mixed, active, thermic Typic Hapludalf common throughout the area where all leaves were collected. The sediment was sieved $(4 \mathrm{~mm}$ ) and spread in a $2.5 \mathrm{~cm}$ thick layer below each leaf sample in $17 \times 26 \mathrm{~cm}$ enamel butcher trays. Water levels were maintained at $10 \mathrm{~cm}$ above the leaf surface throughout the experiment for the SED and DI treatments, and Teflon stir bars were used to keep the leaves submerged.

To assess leaf staining, triplicate measurements of leaf hue, value, and chroma were collected at the initiation of the study and at seven-day intervals using a digital colorimeter (CR-400, Konica Minolta, Osaka, Japan). Submerged leaves were removed from their laboratory dishes, patted dry to remove excess moisture, measured and immediately relocated back to the dish to minimize exposure to the atmosphere. Color measurements utilized the Munsell@ Soil Color system (Gretag and Macbeth 2000). Hue was converted to a standard scoring numerical scale (Melville and Atkinson 1985; Rabenhorst and Parikh 2000). A negative numerical value was assigned to hue measurements occurring below the red range (numerical value $=0$ ). Examples of the Munsell hue conversions include $5 \mathrm{GY}=35,5 \mathrm{Y}=25,5 \mathrm{YR}=15$, $5 R=5,5 R P=-5$ and $5 P=-15$.

Statistical comparisons utilized analysis of multivariate repeated measures (ANOVA) in SPSS version 26. ANOVA tests evaluated differences in Munsell hue, value, and chroma at each seven-day time interval across all five treatments. Post-hoc testing applied the Tukey HSD test. Results
( $p$-values) of all statistical tests are available in Supplemental Tables S1-S8.

\section{Results}

Prior to initiation of the study, samples exhibited no differences in color between replicate leaves of the same species. Each of the leaf species exposed to inundation (DI, SED, LF) displayed decreases in hue, value, and chroma during the study, although the magnitude and rate of color change varied with treatment and species (Figs. 1 and 2). Conversely, leaves exposed to no inundation (UP, UP-SED) showed only minor fluctuations in Munsell hue, increases in value, and limited but steady declines in chroma. Leaf color changes occurred more rapidly and to a larger extent under simulated wetland treatments compared with the simulated upland treatments.

No significant differences in leaf color were detected at day 7 day ( $p \geq 0.352$ for all parameters; Tables S1-S8), but after 14 days of inundation leaves exposed to simulated wetland treatments SED (mean \pm standard deviation $=16.3 \pm 3.7)$ and CF (11.0 \pm 2.1$)$ displayed lower Munsell hues than the simulated upland treatments UP $(33.2 \pm 2.0)$ and UP-SED (31.2 \pm 3.4$)$ across all leaf species $(p \leq 0.009)$. Differences in hue persisted at each seven-day sample interval throughout the remainder of the study ( $p \leq 0.004$ at each interval), including at the conclusion of the experiment on day 56 when SED $(-8.9 \pm 1.0)$ and LF $(-9.7 \pm 1.1)$ treatments were lower than the UP $(31.6 \pm 1.1)$ and UP-SED $(29.3 \pm 2.0)$ treatments. The leaf colors in the simulated wetland treatments shifted hue from the green-yellow range (numerical scale 30-40) at the beginning of the study to the red-purple range (numerical scale -5), causing the leaves to appear very dark or black to observers. No such color shift occurred in the upland treatments. The DI treatment displayed a decline in hue, but the decrease took longer to occur and failed to reach the dark, purple hues observed in the simulated wetland treatments.

Chroma measurements showed similar patterns, with SED $(0.9 \pm 0.1)$ and LF $(0.5 \pm 0.1)$ treatments decreasing and becoming lower than UP $(2.0 \pm 0.2, p=0.001)$ and UPSED $(1.9 \pm 0.2, p \leq 0.014)$ treatments after 21 days. Wetland treatments continued to display lower chroma than upland treatments $(p \leq 0.029)$ at each time interval throughout the experiment. Decreasing chroma reduces the strength and purity of colors, resulting in leaves that appeared dull, dark, and muted in the simulated wetland scenarios compared with the upland treatments which displayed limited declines in chroma. The chroma of the DI treatment decreased during the study, reaching a minimum of $1.3 \pm 0.3$ after 56 days of inundation, but declines occurred more slowly and to a lesser extent than simulated wetland treatments. 

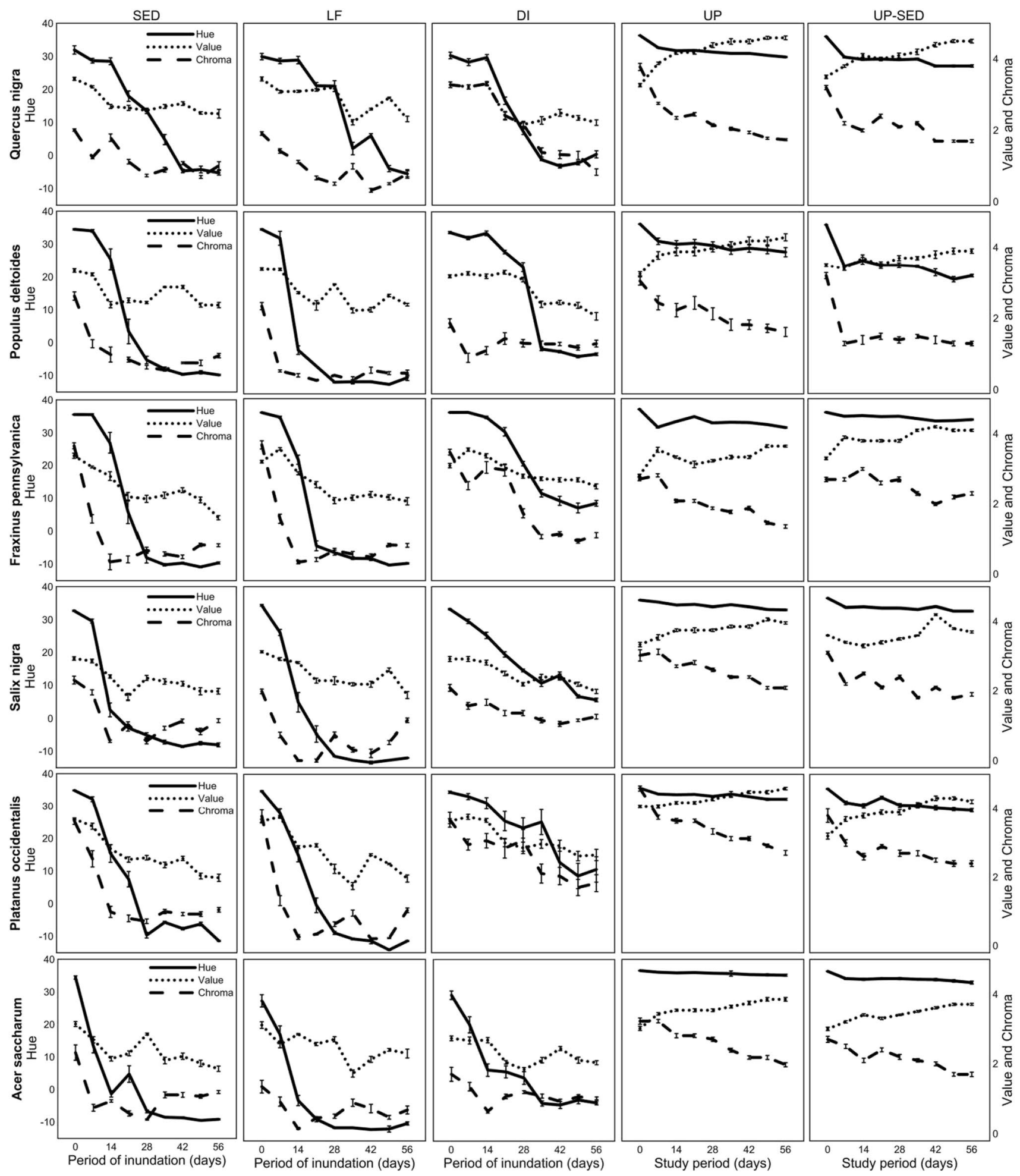

Fig. 1 Munsell hue (left axis), value and chroma (right axis) measurements in SED, LF, DI, UP and UP-SED treatments for the six leaf species examined. Note that SED and LF treatments, simulating wet- land conditions became water-stained, displaying higher magnitude and more rapid color shifts than the DI, UP and UP-SED treatments. Error bars represent on standard deviation 


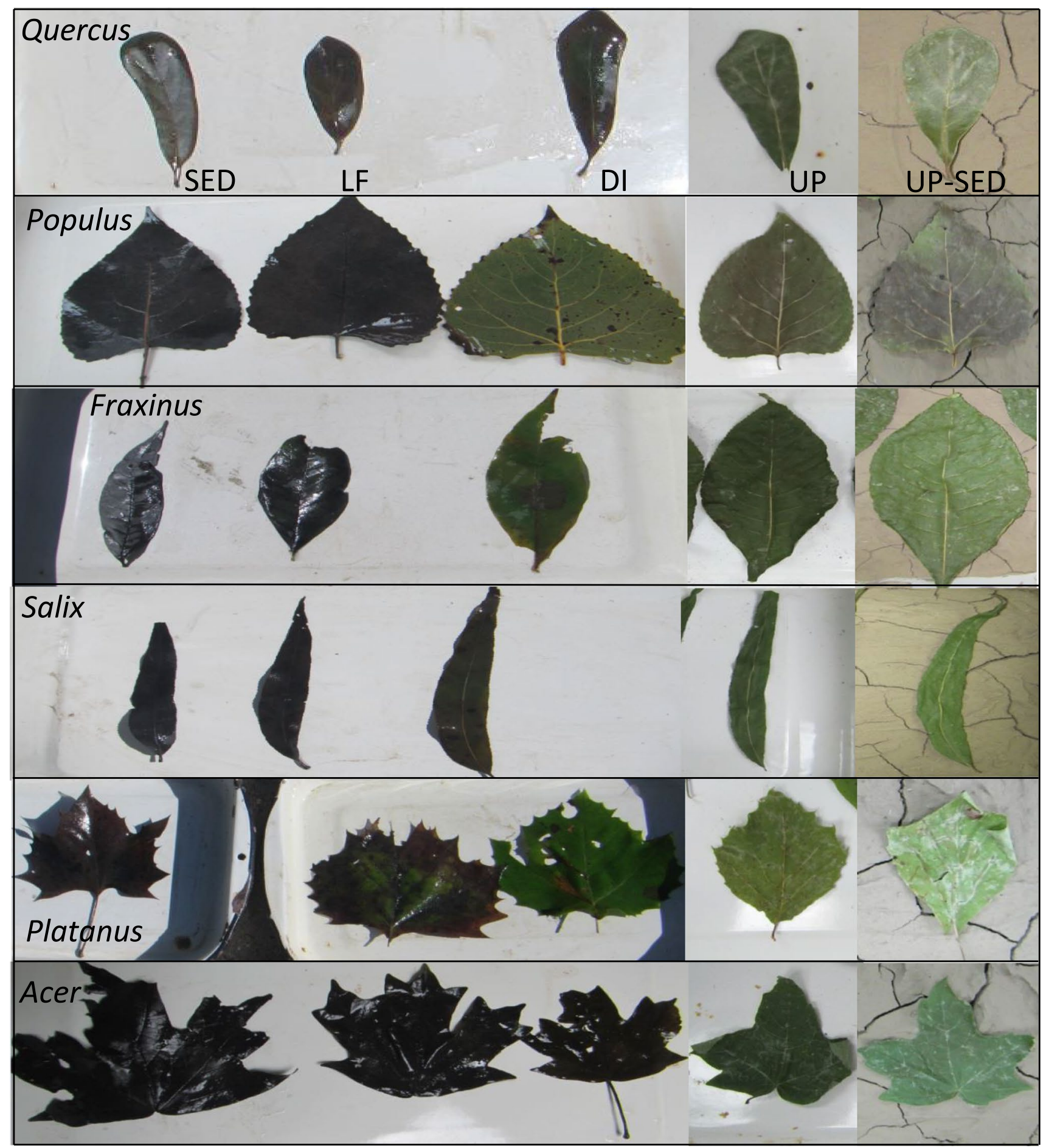

Fig. 2 Example of leaf color change across six species (rows from top to bottom) including Quercus nigra, Populus deltoides, Fraxinus pennsylvanica, Salix nigra, Platanus occidentalis, and Acer saccharum leaves after 21 days across the five treatments examined (columns). Note that the simulated wetland treatments resulted in water-

Following the trends observed from hue and chroma, Munsell value measurements collected under simulated wetland conditions also decreased during the study. Conversely, staining, while the upland treatments exhibited only slight changes in observed colors. The DI treatment induced some color shifts, but to a lesser extent and more slowly than treatments using wetland water and sediment

the simulated upland treatments displayed increases in Munsell value. As a result, SED (2.6 \pm 0.3$)$ and LF $(2.9 \pm 0.1)$ treatments become lower than both the non-inundated UP 
$(3.8 \pm 0.3, p \leq 0.013)$ and UP-SED $(3.7 \pm 0.3, p \leq 0.015)$ treatments after 14 days of inundation. The Munsell value measurements in simulated wetland treatments remained lower than observations made in simulated upland treatments during the remainder of the experiment $(p \leq 0.011$ at each time interval). Decreases in Munsell value indicate a shift toward darker colors, and the leaves exposed to simulated wetland treatments became darker while the simulated upland treatments shifted towards lighter color spaces.

\section{Discussion}

The collective decreases in hue, value, and chroma documented in the simulated wetland (SED) and wetland (LF) treatments resulted in leaves with darker colors, appearing black to the observer (Fig. 2). The SED and LF treatments displayed similar leaf color shifts, suggesting that samples maintained in the laboratory (SED) emulated conditions observed under the field treatment (LF). The quantified color shifts in these two treatments correspond to the qualitative description of "grayish or blackish" water-stained leaves in USACE (2010) and demonstrate that each of the leaf species exposed to wetland conditions became water-stained during the study regardless of its wetland plant indicator rating (e.g., obligate wetland; facultative upland; USACE 2018).

Conversely, none of the leaves in the simulated UP or UPSED treatments exhibited color shifts associated with waterstained leaves. The leaf color responses following exposure to simulated wetland and non-wetland conditions suggest that the colors associated with water-stained leaves only form in wetland environments where prolonged periods of inundation occur. Further, while the DI treatment did induce limited leaf color changes, the magnitude and timing of the color shifts differed from treatments utilizing wetland water and sediments. The different leaf responses in the wetland treatments (SED, LF) and the DI treatment could result from a number of factors, including the presence and abundance of soil microbes in wetland water and sediment, divergent oxidation-reduction potentials, the availability of alternative electron acceptors, or other potential drivers of leaf color change. Additional targeted studies will be required to comprehensively investigate specific mechanisms influencing color shifts under various scenarios.

The capacity of the color measurements to differentiate between leaves exposed to wetland and upland conditions suggests that the Munsell color system may provide a quantitative tool to identify the presence of water-stained leaves based on the combinations of hue, value, and chroma outlined above. This could improve the application of this field indicator of wetland hydrology, which is currently a qualitative observation based on the presence of "grayish or blackish" plant materials. For example, following $\geq 14$ days of inundation all leaves exposed to simulated wetland conditions displayed Munsell hues $\leq 25$ (corresponding to $5 \mathrm{Y}$ or redder colors), values $\leq 3.0$, and chroma $\leq 2.0$. While we do not recommend establishment of a restrictive Munsell color threshold based on the current dataset, which was limited to the evaluation of six deciduous species from a single location, these colors correspond with the field observations made by the authors in a variety of wetland settings across multiple climatic and geographic regions.

Within the current study, the majority of color change occurred within 14-21 days of inundation in simulated wetland treatments as indicated by a decrease in the rate of color change at longer time intervals (Fig. 1). For example, $>50 \%$ of the change in hue, $>66 \%$ of the value change, and $>90 \%$ of the chroma change occurred during the first 21 days under simulated wetland conditions across all of the leaf species evaluated, inducing a color shift that was readily identifiable (Fig. 2). These findings align well with the established technical criteria used to document the presence of wetland hydrology. For example, the National Research Council (1995) reviewed wetland hydrology data and recommendations from a variety of sources published over several decades and determined that the best available science supports a minimum hydroperiod of 14-21 consecutive days of saturation, flooding, or ponding is required to induce wetland hydrology. Similarly, USACE (2005) convened a group of wetland experts to develop a technical threshold for the documentation of wetland hydrology, stating that a site must remain inundated or saturated for " $\geq 14$ consecutive days during the growing season". The finding that most leaf staining occurred with 14-21 consecutive days of simulated wetland hydrology suggests that the formation of water-stained leaves may also provide a useful proxy measurement of the minimum hydroperiod required for wetland identification. Additionally, the observation of water-stained leaf formation (and potential misidentification of wetland hydrology) following infrequent or short duration periods of inundation appears to be limited based on the available data.

Notably, the current study only examined deciduous leaves collected within one region under controlled conditions that may not directly correspond to real-world scenarios. Further research will be required to examine the water-staining process in other leaf types (e.g., succulents, conifers), more complex hydropatterns such as fluctuating periods of inundation and drawdown, and other environmental conditions. For example, we anticipate that warmer temperatures, which increase the rate of microbial activity and chemical reactions, would facilitate the leaf staining process. Also, research could investigate the potential for leaf staining to occur outside of the growing season. Studies evaluating how water-stained leaves form in different wetland types such as seasonally flooded forested wetlands and freshwater tidal swamps with daily inundation would 
also be informative. Additionally, this research utilized fresh leaves which were green at the initiation of the experiments and it would be interesting to replicate the study with older, more decomposed leaves. However, as the first study to examine the water-staining process in a wetland hydrology and delineation context, the available data supports the use of water-stained leaves as a reliable field indicator of wetland hydrology, especially given the similarity in the timeframes required to induce water-stained leaf formation and the technical threshold used to document wetland hydrology in the United States.

\section{Conclusions}

The study demonstrates that continuous inundation induced the formation of water-stained leaves across six tree species under simulated wetland and field conditions. Leaf staining was characterized by a combination of decreasing Munsell hue, chroma, and value that differed from observations made under non-wetland conditions. The 14 to 21-day hydroperiod associated with leaf staining corresponds well with established wetland hydrology criteria, although staining rates likely depend on temperature and other environmental conditions. The study results also suggest that Munsell color measurements can differentiate between leaves exposed to wetland and upland conditions, providing a potential tool to improve quantification and documentation of water-stained leaves as a field indicator of wetland hydrology. Further research may be needed to examine additional leaf growth forms and alternative hydrologic regimes under simulated and real-world scenarios. However, the available data supports the use of water-stained leaves as an effective field indicator of wetland hydrology by demonstrating that environmental factors unique to wetlands induced leaf staining. Additional studies investigating the application of other field indicators of wetland hydrology will help validate wetland delineation techniques and improve wetland and aquatic resource management.

Supplementary Information The online version contains supplementary material available at https://doi.org/10.1007/s13157-021-01498-3.

Acknowledgements The authors thank Christine VanZomeren for helping with leaf color measurements, Mathew Kupchik for contributing to statistical analysis, and Judy Shearer for assisting with laboratory equipment. Special thanks to John Galbraith, Nathan Beane, Darrell Evans, Sydney Bufkin, Kyle Gordon, and the late Chris Noble for comments and recommendations during manuscript preparation.

Authors' contributions JFB conceived and designed the study, interpreted the results, and developed the final manuscript; JPP conducted the study and developed an initial draft manuscript
Funding This research was funded by the U.S. Army Corps of Engineers Engineer Research and Development Center

Data availability All study data has been reported in the manuscript

Code availability NA

\section{Declarations}

Conflicts of interest/Competing interests Authors have no conflicts of interest of competing interests

Ethics approval NA

Consent to participate NA

Consent for publication NA

Open Access This article is licensed under a Creative Commons Attribution 4.0 International License, which permits use, sharing, adaptation, distribution and reproduction in any medium or format, as long as you give appropriate credit to the original author(s) and the source, provide a link to the Creative Commons licence, and indicate if changes were made. The images or other third party material in this article are included in the article's Creative Commons licence, unless indicated otherwise in a credit line to the material. If material is not included in the article's Creative Commons licence and your intended use is not permitted by statutory regulation or exceeds the permitted use, you will need to obtain permission directly from the copyright holder. To view a copy of this licence, visit http://creativecommons.org/licenses/by/4.0/.

\section{References}

Berkowitz JF (2011) Recent advances in wetland delineation - Implications and impact of regionalization. Wetlands 39(3):593-601

Berkowitz JF, Vepraskas MJ, Vaughan KL, Vasilas LM (2021) Development and application of the Hydric Soil Technical Standard. Soil Science Society of America Journal 85(3):469-487

Cowardin LM, Carter V, Golet FC, La Roe TE (1979) Classification of wetlands and deepwater habitats of the United States. U.S. Department of the Interior, Fish and Wildlife Services. FWS/ OBS-79/31. GPO, Washington, DC

Cronk JK, Fennessy MS (2001) Wetland plants: biology and ecology. CRC Press

Environmental Laboratory (1987) US Army Corps of Engineers Wetland Delineation Manual. Technical Report Y-87-1. Army Engineer Waterways Experiment Station, Vicksburg, MS

Faulkner SP, Patrick WH (1992) Redox processes and diagnostic wetland soil indicators in bottomland hardwood forests. Soil Science Society of America Journal 56(3):856-865

Gretag, Macbeth (2000) Munsell® Soil Color Chart. New Windsor, NY

Hurt GW, Brown RB (1995) Development and application of hydric soil indicators in Florida. Wetlands 15(1):74-81

Lichvar RW, Melvin NC, Butterwick ML, Kirchner WN (2012) National wetland plant list indicator rating definitions (No. ERDC/ CRREL-TN-12-1). Hanover NH, Cold Regions Research and Engineering Lab

Megonigal JP, Patrick WH, Faulkner SP (1993) Wetland identification in seasonally flooded forest soils: soil morphology and redox dynamics. Soil Science Society of America Journal 57(1):140-149 
Melville MD, Atkinson G (1985) Soil colour: its measurement and its designation in models of uniform colour space. Journal of Soil Science 36(4):495-512

National Research Council (1995) Wetlands: Characteristics and boundaries. National Academy, Washington

Price JJ, Berkowitz JF (2020) Wetland Functional Responses to Prolonged Inundation in the Active Mississippi River Floodplain. Wetlands 40(6):1949-1956

Price JS, Waddington JM (2000) Advances in Canadian wetland hydrology and biogeochemistry. Hydrological Processes 14(9):1579-1589

Rabenhorst MC, Parikh S (2000) Propensity of soils to develop redoximorphic color changes. Soil Science Society of America Journal 64:1904-1910

Richardson JL, Vepraskas MJ (2001) Wetland soils: genesis, hydrology, landscapes, and classification. CRC Press

Tiner RW (1991) The concept of a hydrophyte for wetland identification. Bioscience 41(4):236-247

Tiner RW (1993) The primary indicators method - a practical approach to wetland recognition and delineation in the United States. Wetlands 13(1):50-64

Tiner RW (1996) Wetland definitions and classifications in the United States. Fretwell, JD et al. (compilers), National Water Summary on Wetland Resources. US Geological Survey. Water-Supply Paper 2425:27-34

Tiner RW (2012) Defining hydrophytes for wetland identification and delineation (No. ERDC/CRREL-CR-12-1). Engineer Research and Development Center Hanover NH Cold Region Research and Engineering Lab

Tiner RW (2016) Wetland Indicators: A guide to wetland identification, delineation, classification, and mapping, 2nd edn. CRC Press

U.S. Army Corps of Engineers (USACE) (2005) Technical standard for water-table monitoring of potential wetland sites. ERDC TNWRAP-05-02. US Army Engineer Research and Development Center, Vicksburg, MS
U.S. Army Corps of Engineers (USACE) (2010) Regional Supplement to the Corps of Engineers Wetland Delineation Manual: Atlantic and Gulf Coastal Plain Region (Version 2.0). J. S Wakeley, R.W. Lichvar, C.V. Noble, (Eds.). ERDC/EL TR-08-28. US Army Engineer Research and Development Center, Vicksburg, MS

U.S. Army Corps of Engineers (USACE) (2018) National Wetland Plant List, version 3.4. U.S. Army Corps of Engineers Engineer Research and Development Center Cold Regions Research and Engineering Laboratory, Hanover, $\mathrm{NH}$

United States Department of Agriculture, Natural Resources Conservation Service (2018) Field indicators of hydric soils in the United States, version 8.2. LM Vasilas, GW Hurt, and JF Berkowitz (eds.) USDA, NRCS, in cooperation with the National Technical Committee for Hydric Soils

Vepraskas MJ (2001) Morphological features of seasonally reduced soils. Wetland soils: Genesis, hydrology, landscapes, and classification, 163-182.

Vepraskas MJ, Faulkner SP (2001) Redox chemistry of hydric soils. Wetland soils: Genesis, hydrology, landscapes, and classification:85-106

Wakeley JS (2002) Developing a "regionalized" version of the Corps of Engineers wetlands delineation manual: Issues and recommendations. ERDC/EL TR-02-20. US Army Engineer Research and Development Center, Vicksburg, MS

Wakeley JS, Sprecher SW, Lynn WC (1996) Preliminary Investigation of Hydric Soil Hydrology and Morphology in the United States. Wetland Research Center Technical Report WRP-DE-13. Waterways Experiment Station, Vicksburg, MS

Publisher's Note Springer Nature remains neutral with regard to jurisdictional claims in published maps and institutional affiliations. 